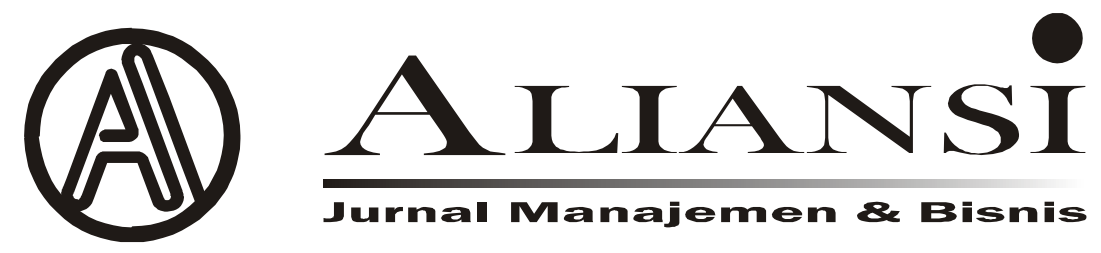

\title{
PENGARUH ETOS KERJA DAN DISIPLIN KERJA TERHADAP KINERJA PEGAWAI (STUDI PADA PEGAWAI DINAS PEKERJAAN UMUM KOTA BEKASI)
}

Oleh : Ifah Masrifah*

email : ifahmasrifah189@gmail.com

\begin{abstract}
The objectives of this study are (1) professional ethics in performing the duties of civil servants in Bukhasi, (2) business principles in relation to public works by employees in Buhasi, (3) personnel of the Bukhasi city administration, work ethics. This study includes causal relationships using a quantitative approach. The survey involved 96 public construction workers in the city of Bekasi. The data were collected using a questionnaire that was checked for validity and reliability. The data analysis method used is multiple regression. Here are the results: (1) work ethic has a positive effect on the work of the staff of the Human Resources Department of the city of Bekasi; This is evidenced by a beta coefficient of $0.256(\hat{a}) . p=0.000$ and $R 2$ is $4.1 \%$. (2) Labor discipline has a positive effect on the productivity of workers in the general construction sector of Bekasi Regent. This is evidenced by the coefficient beta ( $\hat{a}) 0.210, p$ $=0.004$ and $R 22.7 \%$. (3) Work ethics and work discipline have a positive effect on the efficiency of public works in the city of Bekasi. This is evidenced by the beta coefficient $(\hat{a})$ of the work ethic variable 0.234 and $p=0.001$. The beta coefficient ( $\hat{a})$ for the job variable is 0.181 and $p=0.009 .6 .2 \% R 2$.

Keywords: Work Ethic, Work Discipline, and Employee Performance
\end{abstract}

\section{PENDAHULUAN}

Keberadaan Dinas Pekerjaan Umum Kota Bekasi sebagai lembaga pemerintahan wajib melaksanakan tugas di bidang pelayanan masyarakat yaitu: sebagai pembina, pengayom dan pemerhati masalah-masalah pekerjaan umum. Kewenangan Dinas Pekerjaan Umum Kota Bekasi dibentuk untuk mengatur rumah tangga organisasi, serta melaksanakan tugas yang telah diberikan oleh Walikota, yang membawahi empat sub dinas, antara lain: Sub Dinas Pengairan, Sub Dinas Bina Marga, Sub Dinas Cipta Karya, dan Sub Dinas Kebersihan dan Tata Kota. Dalam melayani kepentingan masyarakat tersebut dibutuhkan tenaga kerja/karyawan yang mempunyai kinerja yang tinggi.

Kinerja aparat birokrasi atau pegawai negeri merupakan faktor penting dalam birokrasi pemerintah, karena pegawai negeri adalah unsur pelaksana dan fungsi dari kegiatan pemerintahan antara lain dalam kegiatan pelayanan. Hasil observasi di atas menunjukkan bahwa rendahnya kinerja pegawai ditunjukkan dengan adanya pegawai yang tidak menyelesaikan tugas yang diberikan dengan tepat waktu sebanyak 7 orang $(23,3 \%)$, pegawai yang bekerja tidak sesuai dengan jam kerja yang ditetapkan sebanyak 6 orang $(20,0 \%)$, Pegawai jarang absen jika tidak benar-benar dalam keadaan mendesak sebanyak 8 orang $(26,7 \%)$, pegawai tidak menjalin kerja sama dengan rekan kerja sebanyak 4 orang $(13,3 \%)$, dan adanya pegawai yang tidak senang membantu rekan kerja yang kesulitan dalam bekerja sebanyak 4 orang (13,3\%). Etos kerja pegawai Dinas Pekerjaan Umum Kota Bekasi dapat dilihat dari kerja keras mereka seperti bekerja lembur, namun beberapa pegawai tidak memanfaatkan jam kerja yang ada dan cenderung mengurangi jam kerja mereka. Dari observasi yang dilakukan banyak di antara pegawai tersebut yang mengisi waktu kerjanya dengan duduk-duduk berbincang, ataupun keluar kantor untuk urusan-urusan yang tidak berkaitan dengan tugas pekerjaannya. Pegawai juga memiliki ketekunan yang rendah. Dilihat dari pekerjaan tidak selesai karena dipengaruhi rendahnya disiplin dalam bekerja, rendahnya kepatuhan, rendahnya rasa tanggung jawab, dan tidak menunjukkan kemampuan profesional dalam bekerja.

\footnotetext{
* Dosen Universitas Panca Sakti Bekasi
} 
Tanggung jawab pegawai untuk Dinas Pekerjaan Umum Kota Bekasi masih rendah. Dilihat dari masih adanya sebagian pegawai terlihat tidak mengerjakan tanggung jawab tugasnya dengan sungguh-sungguh, ketika Dekan meminta hasil tanggung jawab tugasnya, pegawai cenderung mengumpulkan dengan asal-asalan, tidak diperiksa sebelum diserahkan kepada pimpinan. Hal ini menunjukkan lemahnya kesungguhan dan ketekunan mereka dalam bekerja.

Kejujuran pegawai masih kurang. Hasil observasi menunjukkan beberapa pegawai yang mencuri waktu pada jam kerja seperti, duduk depan layar komputer, namun mata justru menyasar ke laman-laman media sosial. Hal ini terjadi ketika sedang tidak mood untuk melakukan tugasnya atau bosan dengan tekanan tinggi dari atasan, dan bergosip dengan rekan kerja sampai melupakan kewajiban untuk bekerja. Rendahnya etos kerja pegawai Dinas Pekerjaan Umum Kota Bekasi disebabkan adanya prinsip bahwa bekerja hanya untuk mendapatkan uang, tidak adanya kontribusi dari diri pegawai untuk kemajuan organisasi, dan perasaan jika pekerjaan yang selama ini dijalankan tidak dapat mewujudkan cita-cita yang diinginkan.

Hasil survey tersebut menunjukkan sebanyak 6 orang $(20,0 \%)$ rendahnya disiplin kerja pegawai karena kurangnya kesadaran karyawan dalam melaksanakan tugas, sebanyak 13 orang $(43,3 \%)$ mengatakan bahwa rendahnya disiplin kerja pegawai karena pelanggaran peraturan. Sementara itu, sebanyak 11 orang $(36,7 \%)$ mengatakan bahwa rendahnya disiplin kerja pegawai karena kurangnya kemampuan pegawai dalam melaksanakan tugas.

Berdasarkan fakta yang diperoleh dari Dinas Pekerjaan Umum Kota Bekasi tentang adanya beberapa karyawan yang memiliki kinerja, etos kerja, dan disiplin kerja yang belum maksimal, maka alasan tersebut yang mendasari penelitian ini mengambil judul "Pengaruh Etos Kerja dan Disiplin Kerja terhadap Kinerja Pegawai pada Dinas Pekerjaan Umum Kota Bekasi”.

\section{TINJUAN TEORI}

Syamsi (2001:73) kinerja dapat didefinisikan sebagai tingkat pencapaian hasil atau degree of accomplishment. Bangun (2012:99) mengatakan kinerja adalah hasil pekerjaan yang dicapai seseorang berdasarkan persyaratan-persyaratan pekerjaan, persyaratan biasa disebut dengan standar kerja, yaitu tingkat yang diharapkan suatu pekerjaan tertentu untuk dapat diselesaikan dan di perbandingan atas tujuan atau target yang ingin dicapai. Dari beberapa pengertian di atas, landasan yang digunakan dalam penelitian ini adalah pendapat Mangkunegara (2000: 67) yang mengemukakan kinerja pegawai adalah hasil kerja secara kualitas dan kuantitas yang dicapai oleh seorang pegawai dalam melaksanakan tugasnya sesuai dengan tanggung jawab yang diberikan kepadanya. Jadi dapat ditarik kesimpulan bahwa definisi kinerja adalah hasil kerja pegawai baik kualitas maupun kuantitas yang dicapai oleh pegawai dalam periode tertentu sesuai dengan tanggung jawab yang diberikan.

Indikator yang digunakan dalam penelitian ini merupakan dari indikator-indikator dari Setiawan dan Kartika (2014:1477) yang meliputi: ketepatan penyelesaian tugas, kesesuaian jam kerja, tingkat kehadiran, dan kerja sama antar pegawai.

Etos kerja seseorang erat kaitannya dengan kepribadian, perilaku dan karakter. Setiap orang memiliki internal being yang merupakan siapa dia. Kemudian intenal being menetapkan respons atau reaksi terhadap tuntutan eksternal. Respons internal being terhadap tuntutan eksternal dunia kerja menetapkan etos kerja seseorang (Siregar, 2000). Etos berasal dari bahasa yunani ethos yakni karakter, cara hidup, kebiasaan seseorang, motivasi atau tujuan moral seseorang serta pandangan dunia mereka, yakni gambaran, cara bertindak ataupun gagasan yang paling komprehensif mengenai tatanan. Dengan kata lain etos adalah aspek evaluatif sebagai sikap mendasar terhadap diri dan dunia mereka yang direfleksikan dalam kehidupannya (Khasanah, 2004:8).

Tsamara, (2002) menjabarkan etos kerja yang seharusnya dimiliki oleh seorang pegawai adalah totalitas kepribadian dirinya serta caranya mengekspresikan, memandang, meyakini dan memberikan makna ada sesuatu, yang mendorong dirinya untuk bertindak dan meraih amal yang optimal sehingga pola hubungan antara manusia dengan dirinya dan antara manusia dengan makhluk lainnya dapat terjalin dengan baik.

Apabila dikaitkan dengan situasi kehidupan manusia yang sedang "membangun", maka etos kerja yang tinggi akan dijadikan sebagai prasyarat yang mutlak, yang harus ditumbuhkan dalam kehidupan itu. Karena hal itu akan membuka pandangan dan sikap kepada manusianya untuk menilai tinggi terhadap kerja keras dan sungguhsungguh, sehingga dapat mengikis sikap kerja yang asal-asalan, tidak berorientasi terhadap mutu atau kualitas kerja yang semestinya (Cohen, 2002). 
Menurut Simamora (2004:234) disiplin adalah prosedur yang mengoreksi atau menghukum bawahan karena melanggar peraturan atau prosedur. Disiplin kerja adalah suatu alat yang digunakan para manajer untuk berkomunikasi dengan karyawan agar mereka bersedia untuk mengubah suatu perilaku serta sebagai suatu upaya untuk meningkatkan kesadaran dan kesediaan seseorang menaati semua peraturan perusahaan dan norma-norma sosial yang berlaku (Rivai, 2004:444).

Hasibuan (2004:213) berpendapat bahwa kedisiplinan adalah kesadaran dan kesediaan seseorang menaati semua peraturan perusahaan dan norma-norma sosial yang berlaku. Menurut Handoko (2001) disiplin adalah "kegiatan manajemen untuk menjalankan standar-standar organisasional". Pendapat lain mengatakan bahwa disiplin kerja merupakan "suatu sikap dan perilaku yang berniat untuk menaati segala peraturan organisasi yang didasarkan atas kesadaran diri untuk menyesuaikan dengan peraturan organisasi" (Helmi, 1996).

Disiplin kerja menurut Sinungan (2005) adalah "sebagai sikap mental tercermin dalam perbuatan atau tingkah laku perorangan, kelompok atau masyarakat berupa ketaatan (obedience) terhadap peraturan-peraturan atau ketentuan yang ditetapkan pemerintah atau etik norma dan kaidah yang berlaku dalam masyarakat untuk tujuan tertentu".

Disiplin kerja karyawan sangat penting bagi suatu perusahaan dalam rangka mewujudkan perusahaan. Sikap disiplin kerja yang dimiliki oleh karyawan sangat penting bagi suatu perusahaan dalam rangka mewujudkan tujuan perusahaan. Tanpa disiplin kerja karyawan yang baik sulit bagi suatu perusahaan mencapai hasil yang optimal. Disiplin yang baik mencerminkan besarnya tanggung jawab seseorang terhadap tugas-tugas yang diberikan kepadanya. Hal ini mendorong gairah kerja, semangat kerja dan terwujudnya tujuan perusahaan.

Kedisiplinan suatu perusahaan dikatakan baik, jika sebagian besar karyawan menaati peraturanperaturan yang ada. Hukuman diperlukan dalam meningkatkan kedisiplinan dan mendidik karyawan supaya menaati semua peraturan perusahaan. Pemberian hukuman harus adil dan tegas terhadap semua karyawan. Dengan keadilan dan ketegasan, sasaran pemberian hukuman tercapai. Peraturan tanpa diimbangi dengan pemberian hukuman yang tegas bagi pelanggarannya bukan menjadi alat pendidik bagi karyawan. Tanpa dukungan disiplin karyawan yang baik, sulit bagi perusahaan untuk mewujudkan tujuannya.
Dari berbagai pendapat di atas dapat disimpulkan bahwa disiplin kerja adalah sikap yang tercermin dari perbuatan atau tingkah laku karyawan, berupa kepatuhan atau ketaatan terhadap peraturan dan ketentuan yang ditetapkan oleh perusahaan. Dalam hal ini disiplin tidak hanya dalam bentuk ketaatan saja melainkan juga tanggung jawab yang diberikan oleh organisasi, berdasarkan pada hal tersebut diharapkan efektivitas pegawai akan meningkat dan bersikap serta bertingkah laku disiplin. Motif utama karyawan pada saat ini mungkin dapat berubah untuk hari esok. Perubahan motif dalam bekerja ini dapat terjadi kapan saja setelah satu motif terpenuhi dengan baik sehingga motif yang lain akan menggantikannya. Motif lama yang telah terpuaskan akan menjadi reda sehingga akan mengurangi keinginan karyawan untuk bertindak dan berperilaku bila dibandingkan dengan motif yang baru yang masih belum terpuaskan. Motif karyawan yang selalu berubah-ubah apabila motif yang satu telah terpenuhi sangat mempengaruhi kondisi disiplin kerja para karyawan. Dampak perubahan motif dalam bekerja ini harus mendapat porsi pembinaan dengan prioritas utama dari pihak manajemen.

\section{METODE PENELITIAN}

Penelitian ini termasuk dalam kategori penelitian asosiatif kausal dengan menggunakan pendekatan kuantitatif. Penelitian ini akan menjelaskan hubungan mempengaruhi dan dipengaruhi dari variabel-variabel yang akan diteliti (X), yaitu etos kerja dan disiplin kerja terhadap variabel dependen (Y) kinerja pegawai. Pendekatan kuantitatif digunakan karena data yang akan digunakan untuk menganalisis pengaruh antar variabel dinyatakan dengan angka.

Penelitian dilaksanakan di Dinas Pekerjaan Umum Kota Bekasi dan waktu pelaksanaan pada bulan Februari-Mei 2021. Populasi dari penelitian ini adalah seluruh pegawai Dinas Pekerjaan Umum Kota Bekasi yang berjumlah 86 orang. Dengan demikian jumlah responden yang digunakan dalam penelitian ini sebanyak 86 orang, sehingga penelitian ini disebut penelitian populasi. Teknik pengumpulan data menggunakan kuesioner. Instrumen pada penelitian ini berupa kuesioner, di mana terdapat tiga variabel yaitu etos kerja, disiplin kerja dan kinerja pegawai. Uji coba instrumen dilakukan untuk mengetahui validitas dan reliabilitas suatu instrumen.. Uji instrumen pada penelitian menggunakan IBM SPSS Statistic 23. Dalam penelitian ini, teknik analisis data yang digunakan adalah analisis regresi linier berganda dan menggunakan alat bantu berupa software komputer program IBM SPSS Statistic 23. 


\section{HASIL DAN PEMBAHASAN}

Penelitian ini bertujuan untuk mengetahui: (1) pengaruh etos kerja terhadap kinerja pegawai pada Dinas Pekerjaan Umum Kota Bekasi, (2) pengaruh disiplin kerja terhadap kinerja pegawai pada Dinas Pekerjaan Umum Kota Bekasi, dan (3) pengaruh etos kerja dan disiplin kerja terhadap kinerja pegawai pada Dinas Pekerjaan Umum Kota Bekasi. Subjek dalam penelitian ini adalah seluruh pegawai Dinas Pekerjaan Umum Kota Bekasi yang berjumlah 86 orang. Data yang digunakan dalam penelitian ini adalah data primer. Data primer diperoleh dengan cara menyebar kuesioner di Dinas Pekerjaan Umum Kota Bekasi. Adapun hasil penelitian yang diperoleh dari lapangan disajikan sebagai berikut.

Dalam penelitian ini, menggunakan uji kolmogrovsmirnov dengan hasil sebagai berikut:

Tabel 16. Hasil Uji Normalitas

\begin{tabular}{|l|c|c|}
\hline \multicolumn{1}{|c|}{ Variabel } & Signifikansi & Keterangan \\
\hline Etos Kerja & 0,418 & Normal \\
\hline Disiplin Kerja & 0,367 & Normal \\
\hline Kinerja Karyawan & 0,153 & Normal \\
\hline
\end{tabular}

Sumber: Data Primer 2021

Hasil uji normalitas menunjukkan bahwa semua variabel penelitian mempunyai nilai signifikansi lebih besar dari 0,05 pada $(\mathrm{sig}>0,05)$, sehingga dapat disimpulkan bahwa data penelitian berdistribusi normal, artinya variabel-variabel dalam penelitian mempunyai sebaran distribusi normal.

Hasil rangkuman uji linieritas disajikan berikut ini: Tabel 17. Hasil Uji Linieritas

\begin{tabular}{|c|c|c|}
\hline Variabel & Signifikasi & Keterangan \\
\hline Etos Kerja & 0,136 & Linier \\
\hline Disiplin Kerja & 0,789 & Linier \\
\hline
\end{tabular}

Sumber: Data primer 2021

Hasil uji linieritas pada Tabel 17 di atas dapat diketahui bahwa semua variabel memiliki nilai signifikansi yang lebih besar dari 0,05 (sig $>0,05)$, hal ini menunjukkan bahwa semua variabel penelitian adalah linier, artinya hubungan antara variabel bebas dengan variabel terikat bersifat linear (garis lurus). Hasil uji multikolinieritas untuk model regresi pada penelitian ini disajikan pada Tabel 18 di bawah ini:

Tabel 18. Hasil Uji Multikolinieritas

\begin{tabular}{|c|c|c|c|}
\hline Variabel & Tolerance & VIF & Kesimpulan \\
\hline Etos Kerja & 0,803 & 1,245 & Non Multikolinieritas \\
\hline Disiplin Kerja & 0,803 & 1,245 & Non Multikolinieritas \\
\hline
\end{tabular}

Sumber: Data Primer 2021
Dari tabel 18 di atas terlihat bahwa semua variabel mempunyai nilai toleransi di atas 0,1 dan nilai VIF di bawah 10, sehingga dapat disimpulkan bahwa model regresi pada penelitian ini tidak terjadi multikolinieritas, hal ini menunjukkan variabel-variabel independen tidak saling berkorelasi.

Berikut ini adalah hasil uji heteroskedastisitas terhadap model regresi pada penelitian ini.

Tabel 19. Hasil Uji Heteroskedastisitas

\begin{tabular}{|c|c|c|}
\hline Variabel & Sign. & Kesimpulan \\
\hline Etos Kerja & 0,157 & Non Heteroskedastisitas \\
\hline Disiplin Kerja & 0,101 & Non Heteroskedastisitas \\
\hline
\end{tabular}

Sumber: Data Primer 2021

Tabel 19 di atas menunjukkan bahwa semua variabel mempunyai nilai signifikansi lebih besar dari 0,05 sehingga dapat disimpulkan bahwa model regresi pada penelitian ini tidak terjadi heteroskedastisitas, hal ini berarti bahwa model regresi tidak terjadi ketidaksamaan varians dari residual satu pengamatan ke pengamatan yang lain.

Pengujian hipotesis dilakukan untuk menguji hipotesis yang diajukan. Hipotesis yang diajukan dalam penelitian ini terkait pengaruh etos kerja dan disiplin kerja terhadap kinerja pegawai pada Dinas Pekerjaan Umum Kota Bekasi. Teknik analisis data yang digunakan untuk menguji hipotesis adalah regresi berganda. Berikut ini hasil analisis regresi berganda yang dilakukan dengan menggunakan program SPSS 20.00 for Windows.

Tabel 20. Rangkuman Hasil Analisis Regresi

\begin{tabular}{|c|c|c|c|c|}
\hline \multirow{2}{*}{$\begin{array}{l}\text { Independen dan } \\
\text { Kontrol Variabel }\end{array}$} & \multicolumn{4}{|c|}{ Kinerja Karyawan } \\
\hline & Model 1 ( $\beta$ ) & Model 2 ( $\beta$ ) & Model 3 ( $\beta$ ) & Model 4 ( $\beta$ ) \\
\hline Jènis Kẹlàmin & $0,303^{* * *}$ & $0,257^{* * *}$ & $0,248^{* * *}$ & $0,213 * *$ \\
\hline Usia & $0,202^{* *}$ & $0,176^{* *}$ & $0,191 * *$ & $0,169 * *$ \\
\hline Pendidikan & $0,374^{* * *}$ & $0,319^{* * *}$ & $0,311^{* * *}$ & $0,269 * * *$ \\
\hline Status Pernikahan & $0,271^{* 4}$ & $0,193^{* *}$ & $0,229 * *$ & $0,164^{*}$ \\
\hline Etos Kerja & & $0,256^{* * *}$ & & $0,234^{* *}$ \\
\hline Disiplin Kerja & & & $0,210^{* *}$ & $0,1 \$ 1^{* *}$ \\
\hline $\mathrm{R}^{2}$ & $0,720^{* * *}$ & $0,762^{* * *}$ & $0,747^{* *}$ & $0,782^{* * *}$ \\
\hline$\Delta \mathrm{R}^{2}$ & 0,720 & 0,041 & 0,027 & 0,062 \\
\hline
\end{tabular}

Sumber: Data Primer 2021

Hasil penelitian menunjukkan bahwa bahwa nilai koefisien beta ( $\hat{a})$ sebesar 0,256 dan $p=0,000$; hal ini menunjukkan bahwa etos kerja berpengaruh positif terhadap kinerja pegawai pada Dinas Pekerjaan Umum Kota Bekasi. Kontribusi pengaruh etos kerja terhadap kinerja karyawan sebesar ("R2) 0,041 atau $4,1 \%$; maka penelitian ini berhasil membuktikan 
hipotesis pertama. Nilai koefisien regresi sebesar 0,256 menunjukkan bahwa apabila etos kerja meningkat sebesar 0,256; maka kinerja karyawan meningkat sebesar 0,256.

Hasil penelitian menunjukkan bahwa koefisien beta (â) sebesar 0,210 dan $\mathrm{p}=0,004$; hal ini menunjukkan bahwa disiplin kerja berpengaruh positif terhadap kinerja pegawai pada Dinas Pekerjaan Umum Kota Bekasi. Kontribusi pengaruh disiplin kerja terhadap kinerja karyawan sebesar ("R2) 0,027 atau 2,7\%; maka penelitian ini berhasil membuktikan hipotesis kedua. Nilai koefisien regresi sebesar 0,210 menunjukkan bahwa apabila disiplin kerja meningkat sebesar 0,210; maka kinerja karyawan meningkat sebesar 0,210 .

Hasil penelitian menunjukkan bahwa koefisien beta (â) pada variabel etos kerja sebesar 0,234 dan $\mathrm{p}=0,001$; dan koefisien beta (â) pada variabel disiplin kerja sebesar 0,181 dan $p=0,009$; hal ini menunjukkan bahwa etos kerja dan disiplin kerja berpengaruh positif secara simultan terhadap kinerja pegawai pada Dinas Pekerjaan Umum Kota Bekasi, maka penelitian ini mampu membuktikan hipotesis ketiga. Kontribusi pengaruh etos kerja dan disiplin kerja terhadap kinerja karyawan sebesar (" $\left.R^{2}\right)$ 0,062 atau $6,2 \%$.

\section{KESIMPULAN}

Berdasarkan hasil penelitian dan pembahasan, maka dapat ditarik beberapa kesimpulan sebagai berikut.

1. Etos kerja berpengaruh positif terhadap kinerja pegawai pada Dinas Pekerjaan Umum Kota Bekasi. Hal ini dibuktikan dengan koefisien beta sebesar (â) sebesar 0,256 dan $\mathrm{p}=0,000$. Kontribusi pengaruh etos kerja terhadap kinerja karyawan sebesar (" $\left.\mathrm{R}^{2}\right)$ 0,041 atau 4,1\%.

2. Disiplin kerja berpengaruh positif terhadap kinerja pegawai pada Dinas Pekerjaan Umum Kota Bekasi. Hal ini dibuktikan dengan koefisien beta sebesar (â) 0,210 dan $p=0,004$. Kontribusi pengaruh motivasi kerja terhadap kinerja karyawan sebesar (" $\left.\mathrm{R}^{2}\right)$ 0,027 atau 2,7\%.

3. Etos kerja dan disiplin kerja berpengaruh positif secara simultan terhadap kinerja pegawai pada Dinas Pekerjaan Umum Kota Bekasi. Hal ini dibuktikan dengan koefisien beta (â) pada variabel etos kerja sebesar 0,234 dan $p=0,001$; dan koefisien beta (â) pada variabel disiplin kerja sebesar 0,181 dan $\mathrm{p}=0,009$. Kontribusi pengaruh disiplin kerja dan motivasi kerja terhadap kinerja karyawan sebesar (" $\left.\mathrm{R}^{2}\right)$ 0,062 atau 6,2\%.

\section{REFFERENSI}

Ali Muhson. (2005). Aplikasi Komputer. Yogyakarta: Universitas Negeri Yogyakarta. Diktat.

Anoraga, Panji. 1992. Psikologi Kerja. Jakarta: Penerbit PT. Rineka Cipta.

As'ad, Moch. 2005. Psikologi Industri. Yogyakarta: Liberty.

Bangun, Wilson. 2012. Manajemen Sumber Daya Manusia. Bandung: Erlangga. BPS United Nation Population Fund. (2015). Analisis Korelasi dan Regresi Linier. Artikel. Jakarta.

Ferdinand. 2006. Metode Penelitian Manajemen. Semarang: Badan Penerbit Universitas Diponegoro.

Geertz, C., 1973, Interpretations of Culture, Basic Book Inc., New York.

Ghozali, Imam. 2011. Apkikasi Analisis Multivariate dengan Program IBM SPSS. Semarang: Badan Penerbitan Universitas Diponegoro.

Handoko, T. Hani. (2008). Manajemen Personalia dan Sumber Daya Manusia. Yogyakarta: BPFE.

Hasibuan, Malayu S.P. 2004. Manajemen Sumber Daya Manusia. Jakarta: Bumi Aksara.

Hasibuan, Malayu P. 2013. Manajemen Sumber Daya Manusia. Jakarta: PT Bumi Aksara.

Jogiyanto (2011). Metode Penelitian Bisnis. Yogyakarta : BPFE

Khasanah, Uswatun. 2004. Etos Kerja Sarana Menuju Puncak Prestasi.Yogyakarta: Harapan Utama.

Mahmudi. 2010. Manajemen Kinerja

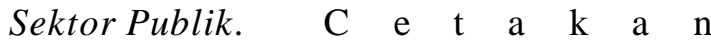
Pertama.Yogyakarta: BPFE.

Mangkunegara, Anwar Prabu. 2005. Manajemen Sumber Daya Manusia.Bandung: PT. Remaja Rosdakarya.

Mangkuprawira, Sjafri \& Hubeis, Aida Vitayala. 2007. Manajemen Mutu Sumber Daya Manusia Cetakan Pertama. Bogor: Ghalia Indonesia.

Manullang. 2010. Dasar-Dasar Manajemen. Yogyakarta: Ghalia Indonesia.

Rahardjo, Dawam. 2001. Etika Ekonomi dan Manajemen. Yogyakarta: Tiara Wicana.

Reilly. 2003. Manajemen Sumber Daya Manusia. Jakarta: Prestasi Pustaka.

Rivai, Veithzal. 2004. Manajemen Sumber Daya Manusia Untuk Perusahaan.Jakarta: Muri Kencana. 
Santosa, Purbayu Budi \& Ashari. (2005). Analisis Statistik dengan Microsoft Excel dan SPSS. Yogyakarta : Penerbit Andi.

Sastrohadiwiryo, Siswanto. (2003). Manajemen Tenaga Kerja Indonesia Pendekatan Administratif dan Operasional. Jakarta: Bumi Aksara.

Simamora, H. 2004. Manajemen Sumber Daya Manusia. Yogyakarta: STIE YKPN.

Sinamo, Jansen H. 2011. Etos Kerja Profesional Navigator Anda Menuju Sukses.PT Spirit Mahardika. Jakarata.

Sinamo, Jansen. 2005. Delapan Etos Kerja Professional. Jakarta: Institut. Sinungan, Muchdarsyah. (2003). Produktivitas Apa dan Bagaimana. Jakarta:Bumi Aksara.
Soewarso, Rahardjo, Subagyo, dan Utomo. 1995. Persepsi Tentang Etos Kerja Kaitannya dengan Nilai Budaya Masyarakat. Jakarta: CV. Bupara Nugraha.

Sugiyono. 2012. Metode Penelitian Admisistrasi. Bandung : CV Alfabeta.

Syamsi, Ibnu. 2001. Organisasi dan Manajemen, Fisipol UGM, Yogyakarta.

Tasmara, Toto. 2002. Membangun Etos Kerja Islam. Jakarta: Gema Insani Pers.

Wirawan. 2009. Evaluasi Kinerja Sumber Daya Manusia. Jakarta: Salemba Empat. 